Short Communication

\title{
AGE RELATED DIFFERENCE IN THE LIPID PROFILE IN NORMAL HEALTHY WOMEN
}

\author{
Deepti G.I. ${ }^{1}$, Sukanya Shetty ${ }^{2}$, Ashalatha V. Rao ${ }^{3}$, Sarfraz Ahmad ${ }^{4}$ \\ ${ }^{184}$ P.G. Students, ${ }^{2}$ Professor \& HOD, ${ }^{3}$ Professor, Department of Biochemistry \\ K.S. Hegde M edical Academy, Nitte University, Deralakatte \\ M angalore - 575 018, Karnataka, India. \\ Correspondence : \\ Sukanya Shetty \\ Professor \& HOD, Department of Biochemistry, K. S. Hegde M edical Academy, \\ Nitte University, Deralakatte, M angalore-575018, Karnataka, India \\ M obile: +91 9986465255 E-mail : hod.bio.kshema@ nitte.edu.in
}

\begin{abstract}
:
Background and objectives : Lipid disorder is a major risk factor for the progression of coronary artery disease. Age alone is a significant predictor of CVD risk in men and women. Before menopause, women have a much lower risk for cardiovascular events compared with men of their age. Reasons for protection from CVD in premenopausal women are complex, but a significant contribution can be assigned to the greater high-density lipoprotein (HDL) levels in younger women, which is an effect of estrogen.
\end{abstract}

Methods : Fasting blood samples were collected from 40 healthy individuals ( 40 females divided into 2 groups according to age). Serum total cholesterol, triglycerides, and HDL- Cholesterol were estimated by enzymatic methods and LDL was calculated by Friedewald's equation.

Results : The result showed increase in total cholesterol, triglyceride and LDL-Cholesterol and decrease in HDL-Cholesterol in women in perimenopausal period as compared to women in the younger age group.

Conclusion: It can be concluded that serum lipid profile changes can possibly be mediated by changing hormonal profile, especially estrogen which has role in lipid metabolism and indirectly on coronary artery disease.

Keywords: Coronary artery disease, Friedewald's equation, perimenopausal period.

\section{Introduction:}

A Woman, from her intrauterine life till the end of life, experiences different stages in her reproductive life, under the influence of female hormones, which is a physiological process. ${ }^{1}$

The sex hormones which are secreted in minute quantities undergo changes in levels according to different phases of her reproductive life. They not only play an important role in women's reproductive life but also influence metabolism in a significant way. They play an important role in lipid

\begin{tabular}{|c|}
\hline Access this article online \\
\hline Quick Response Code \\
\hline
\end{tabular}

During the menopausal transition, more erratic fluctuations in female reproductive hormones are seen. ${ }^{2}$

A more rapid depletion of ovarian follicles starts in the late 30 s and early 40 s and continues until a point at which the menopausal ovary is virtually devoid of follicles.

These changes, including the increase in FSH levels, reflect the reduced quality and capability of aging follicles to secrete inhibin ${ }^{4}$. As follicular depletion continues, episodes of anovulation become more common ${ }^{5}$.

Cardiovascular disease (CVD), including coronary heart disease, congestive heart failure, and stroke, is the leading cause of death in both men and women ${ }^{8}$.

Risk factors are the same for men and women and include family history of cardiovascular disease, hypertension, smoking, diabetes mellitus, abnormal cholesterol/ lipoprotein profile, and obesity. 
Age alone is a individual risk factor of CVD in men and women.

The risk of CVD increases exponentially for women as they enter menopause and estrogen levels decline $e^{9,10}$.

This becomes vitally important for women in menopausal transition, when preventive measures can significantly improve both the quality and the quantity of their lives.

Women in younger age group, have a much lower risk for cardiovascular events compared with men of their age. Reasons for protection from CVD in younger women are complex, but a significant contribution can be atributted to the greater high-density lipoprotein (HDL) levels in younger women, which is an effect of estrogen.

Moreover, total cholesterol and low-density lipoprotein (LDL) levels are lower in premenopausal women than in men of same age group ${ }^{11}$.

But, with the subsequent decrease in estrogen, this favorable effect on lipids is lost. High-density lipoprotein levels decrease and total cholesterol levels increase.

Despite these changes in atherogenic lipids following menopause, total cholesterol and LDL levels can favorably be reduced by dietary modifications, estrogen treatment, and lipid-lowering medications ${ }^{9}$.

The result showed increase in total cholesterol, triglyceride and LDL-Cholesterol and decrease in HDL-Cholesterol in women in perimenopausal period as compared to women in the younger age group.

\section{Material and methods:}

40 healthy women were randomly selected for the study, and divided in two groups.

Group1: women in 20-35yrs

Group 2: women in 35-50yrs

2mlof fasting blood (8-12hrs fasting) was collected using sterile dry vaccutterain syringe, centrifuged within $30 \mathrm{mins}$ and following parameters were analyzed

1) Serum total cholesterol by CHOP-PAP method
2) Serum Triglycerides by GPO-Trinder method

3) HDL-Cholesterol by Direct enzymatic method

4) LDL was calculated by Friedewald's equation

\section{Statistical analysis:}

Data was analyzed statistically by SPSS17

Mean, standard deviation, and standard error were determined for each group.

Comparison of differences in mean of these groups was analyzed using students - $t$ test and $p$ - value was calculated. P-value of $\varangle$.05 was considered as significant.

\section{Results:}

Significant increase in Total Cholesterol, Triglyceride, and LDL and decrease in HDL were observed in women in menopausal transition period compared to women in younger age group. This is showed in Table no 1 and Figure 1.

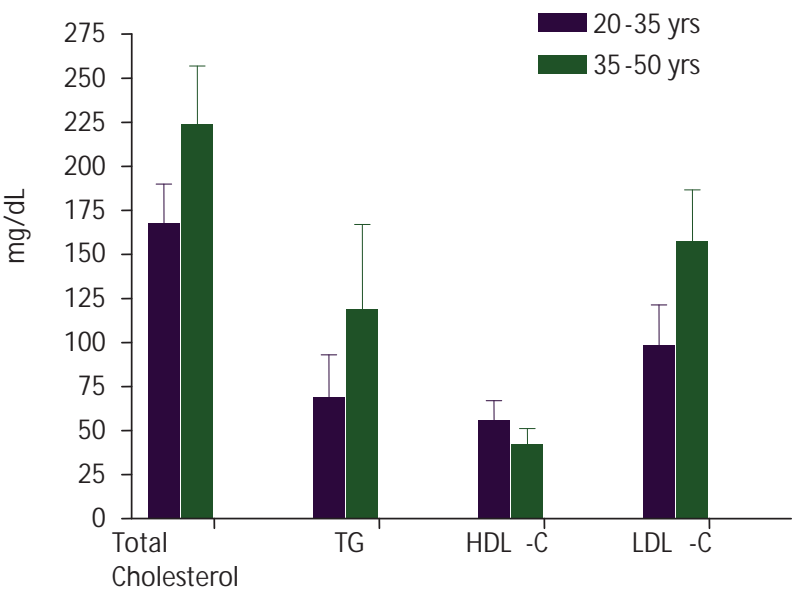

Fig 1: Bar diagram showing comparison of total cholesterol, triglyceride, HDL and LDLin group 1 and 2.

\begin{tabular}{|c|c|c|c|}
\hline $\begin{array}{l}\text { Biochemical } \\
\text { parameters } \\
\text { (Mean } \pm S D)\end{array}$ & $\begin{array}{l}\text { Group } 1 \text { ( } n=20 \text { ) } \\
\text { Age 20-35 yrs }\end{array}$ & $\begin{array}{l}\text { Group } 2 \text { ( } n=20) \\
\text { Age 35-50yrs }\end{array}$ & P-value \\
\hline $\begin{array}{l}\text { Total cholesterol } \\
(\mathrm{mg} / \mathrm{dl})\end{array}$ & $167.80 \pm 22.16$ & $223.65 \pm 33.20$ & $\varangle .0001^{*}$ \\
\hline $\begin{array}{l}\text { Triglyceride } \\
\text { (mg/dl) }\end{array}$ & $68.90 \pm 24.08$ & $119.10 \pm 47.88$ & $\varangle .0001 *$ \\
\hline $\begin{array}{l}\mathrm{HDL}-\mathrm{C} \\
(\mathrm{mg} / \mathrm{dl})\end{array}$ & $56.1615 \pm 10.70$ & $42.1500 \pm 9.05$ & $\varangle .0001 *$ \\
\hline $\begin{array}{l}\text { LDL-C } \\
(\mathrm{mg} / \mathrm{dl})\end{array}$ & $98.6850 \pm 22.55$ & $157.6700 \pm 28.94$ & $\varangle .0001 *$ \\
\hline
\end{tabular}

Table 1 shows mean, standard deviation, and p-value for TC, TG, HDL, LDLin groupl and group2 


\section{Discussion:}

So far comparison has been made between the lipid profiles in women of pre-menopausal and postmenopausal age groups. In present study we have compared the lipid profiles of young women and women in perimenopausal age group.

The results in present study showed total cholesterol, and LDL-C increased in menopausal transition period, this is consistent with results from studies suggesting that increases in total cholesterol and low density lipoprotein cholesterol are gradual, occurring late in the menopause transition. Matthews et al. ${ }^{15}$ reported that the transition from pre- to early perimenopause was not associated with significant changes in low density lipoprotein cholesterol, with changes occurring later in the transition. A small prospective study has shown a gradual increase in low density lipoprotein cholesterol during the menopause transition that continues during the year following menopause. Another study concluded that LDL increases significantly from reproductive period to postmenopausal period. The rise in LDLcan also be attributed to age but the significant raise after menopause is also attributed to hormone levels. ${ }^{1}$

There was lowered LDL-C levels after the treatment with oral estrogen in postmenopausal women, so increase in LDL-C in present syudy can be attributed to the hormonal changes especially estrogen. High estrogen level in younger women has a beneficial effect lowering the LDL-C by acting on LDL receptors ${ }^{(18)}$

We also observed increase in triglyceride, which could be due to hormonal effect on the lipid metabolism independent of age or can be attributed to age as given by few authors. Gandhi B M demonstrated Triglyceride in plasma increased with age. ${ }^{17}$

\section{References:}

1. V Bhagya, N R Hemalatha, H B Veeranna, V Banu. Serum lipid profile in prepubertal, reproductive and postmenopausal women .IntJ Biol M ed Res. 2011; 2(3): 639-642

2. Jain A, Santoro N. Endocrine mechanisms and management for abnormal bleeding due to perimenopausal changes. Clin Obstet Gynecol. 2005; 48:29

3. Santoro N, Brown JR, Adel T. Characterization of reproductive
We also observed decrease in HDL-cholesterol in perimenopausal women as compared to younger women. As few studies have shown ${ }^{(18,21)}$, that oral cyclical estrogen sulphate raised HDL-C. Increases in the HDL-C is caused by increased production of apo Aland decreased hepatic lipase activity, hence, this decrease is attributed to hormonal changes. One study showed HDL-C increases upto menopause and later decreases. This is due to hormonal changes. ${ }^{1}$ but in present study there was significant decrease in HDL-C in perimenopausal period itself rather than in postmenopausal period.

The average HDL cholesterol in women is 55 to $60 \mathrm{mg} / \mathrm{dL}$ and a decrease in $\mathrm{HDL}$ cholesterol of $10 \mathrm{mg} / \mathrm{dL}$ increases coronary heart disease risk by 40 to 50 percent. ${ }^{14}$

The risk of CVD increases exponentially for women as they enter menopause and estrogen levels decline. This becomes vitally important for women in menopausal transition, when preventive measures can significantly improve both the quality and the quantity of their lives ${ }^{9,10}$

As the age advances the level of estrogen deceases and significantly decreases after menopause, this causes increase in the total cholesterol, LDL-C, but decrease in HDL-C.

\section{Conclusion:}

Present study showed significant difference in cholesterol and lipoproteins in younger women in the age group of 20 $35 y$ rs and women in the menopausal transition period.

Hence regular monitoring of women in menopausal transition with lipid profile would be helpful to prevent the age related risk of coronary heart disease.

\section{Limitation of study:}

Serum estrogen levels have not been estimated.

hormone dynamics in the peimenopausal. J.Clin.Endocrinol Metab. 1996;81:1495

4. Reyes $\mathrm{Fl}$, Winter JS, Faiman C. Pituitary-ovarian relationships preceding the menopause. I. A cross-sectional study of serum folliclestimulating hormone, luteinizing hormone, prolactin, estradiol, and progesterone levels. Am J Obstet Gynecol.1997; 129:557

5. Roseff SJ, Bangah ML, Kettel LM. Dynamic changes in circulating 
inhibin levels during the luteal-follicular transition of the human menstrual cycle.J Clin Endocrinol M etab.1998; 69:1033, 198

6. Labrie F, Belanger A, Cusan L. M arked decline in serum concentrations of adrenal C19 sex steroid precursors and conjugated androgen metabolites during aging.J Clin Endocrinol M etab.1997; 82:2396

7. Burger HG, Dudley EC, Cui J. A prospective longitudinal study of serum testosterone, dehydroepiandrosterone sulfate, and sex hormonebinding globulin levels through the menopause transition. J Clin Endocrinol M etab. 2000; 85:2832

8. Minino AM, Arias E, Kochanek KD. Deaths: final data for 2000. Natl Vital Stat Rep.2002; 50:1

9. Matthews KA, Wing RR, Kuller $L H$, et al: Influence of the perimenopause on cardiovascular risk factors and symptoms of middle-aged healthy women. Arch Intern M ed1994; 154:2349

10. Van Beresteijn EC, Korevaar JC, Huijbregts PC. Perimenopausal increase in serum cholesterol: a 10-year longitudinal study. Am J Epidemiol.1993; 137:383

11. Jensen J, Nilas $L$, Christiansen $C$. Influence of menopause on serum lipids and Lipoprotein. Maturitas.1990; 12(4):321

12. Matthews KA, M eilahn E, Kuller LH. Menopause and risk factors for coronary heart disease. N EnglJ M ed.1989; 321:641.

13. Jacobs DR Jr., M ebane IL, Bangdiwala SI, et al: High density lipoprotein cholesterol as a predictor of cardiovascular disease mortality in men and women: the follow-up study of the Lipid Research Clinics
Prevalence Study. Am J Epidemiol.1990; 131:32

14. Kannel WB. Metabolic risk factors for coronary heart disease in women: perspective from the Framingham study. Am Heart J. 1987;114:413

15. Goswami K, Bandyopadhyay A. lipid profile in middle class Bengali population of Kolkata. Indian J clin Biochem.2000;18(2):127-30.

16. Gandhi B M. lipoprotein composition of normal healthy subjects in northern India. Ind T M ed Res.1982; 75:393-401.

17. Gupta KK, Chaugh SK. Study of lipid profile of Indian children born of parents free from both coronary artery disease and coronary risk. Indian Heart J.1996;48:545

18. Notelovitz M , Katz-kamp S. Effect of cyclic estrone sulfate treatment on lipid profiles of postmenopausal women with elevated cholesterol levels. Obstetrics and Gynecology .1990;76:65-70

19. Nebrand C, Lidfelt J, Nyber P, Schersten B. Serum lipids and lipoproteins in relation to endogenous and exogenous female steroids and age. The women's Health in Leend area(WHILA) study. M aurietas .2004;15;48(2):161-9

20. Bonithon-Koop C, Scarabin P Y, Darne B,Malniejac A. Menopause related changes in lipoproteins and some other cardiovascular risk factors. Int J epidemiol.1990;19(1):42-48

21. Farish $E$, Fletcher $C D$. The effects of hormone implants on serum lipoproteins and steroid hormones in bilaterally ooporectomised women. Acta Endocrinol (copenh).1984;106(1):116-20 